\title{
Universal health coverage and intersectoral action for health: key messages from Disease Control Priorities, 3rd edition
}

\author{
Dean T Jamison, Ala Alwan*, Charles N Mock*, Rachel Nugent*, David Watkins*, Olusoji Adeyi, Shuchi Anand, Rifat Atun, Stefano Bertozzi, \\ Zulfiqar Bhutta, Agnes Binagwaho, Robert Black, Mark Blecher, Barry R Bloom, Elizabeth Brouwer, Donald A P Bundy, Dan Chisholm, Alarcos Cieza, \\ Mark Cullen, Kristen Danforth, Nilanthi de Silva, Haile T Debas, Peter Donkor, Tarun Dua, Kenneth A Fleming, Mark Gallivan, Patricia J Garcia, \\ Atul Gawande, Thomas Gaziano, Hellen Gelband, Roger Glass, Amanda Glassman, Glenda Gray, Demissie Habte, King K Holmes, Susan Horton, \\ Guy Hutton, Prabhat Jha, Felicia M Knaul, Olive Kobusingye, Eric L Krakaver, Margaret E Kruk, Peter Lachmann, Ramanan Laxminarayan, \\ Carol Levin, Lai Meng Looi, Nita Madhav, Adel Mahmoud, Jean Claude Mbanya, Anthony Measham, María Elena Medina-Mora, Carol Medlin, \\ Anne Mills, Jody-Anne Mills, Jaime Montoya, Ole Norheim, Zachary Olson, Folashade Omokhodion, Ben Oppenheim, Toby Ord, Vikram Patel, \\ George C Patton, John Peabody, Dorairaj Prabhakaran, Jinyuan Qi, Teri Reynolds, Sevket Ruacan, Rengaswamy Sankaranarayanan, \\ Jaime Sepúlveda, Richard Skolnik, Kirk R Smith, Marleen Temmerman, Stephen Tollman, Stéphane Verguet, Damian G Walker, NeffWalker, \\ Yangfeng Wu, Kun Zhao
}

The World Bank is publishing nine volumes of Disease Control Priorities, 3rd edition (DCP3) between 2015 and 2018. Volume 9, Improving Health and Reducing Poverty, summarises the main messages from all the volumes and contains cross-cutting analyses. This Review draws on all nine volumes to convey conclusions. The analysis in DCP3 is built around 21 essential packages that were developed in the nine volumes. Each essential package addresses the concerns of a major professional community (eg, child health or surgery) and contains a mix of intersectoral policies and healthsector interventions. 71 intersectoral prevention policies were identified in total, 29 of which are priorities for early introduction. Interventions within the health sector were grouped onto five platforms (population based, community level, health centre, first-level hospital, and referral hospital). DCP3 defines a model concept of essential universal health coverage (EUHC) with 218 interventions that provides a starting point for country-specific analysis of priorities. Assuming steady-state implementation by 2030, EUHC in lower-middle-income countries would reduce premature deaths by an estimated 4.2 million per year. Estimated total costs prove substantial: about $9 \cdot 1 \%$ of (current) gross national income (GNI) in low-income countries and $5 \cdot 2 \%$ of GNI in lower-middle-income countries. Financing provision of continuing intervention against chronic conditions accounts for about half of estimated incremental costs. For lower-middle-income countries, the mortality reduction from implementing the EUHC can only reach about half the mortality reduction in non-communicable diseases called for by the Sustainable Development Goals. Full achievement will require increased investment or sustained intersectoral action, and actions by finance ministries to tax smoking and polluting emissions and to reduce or eliminate (often large) subsidies on fossil fuels appear of central importance. DCP3 is intended to be a model starting point for analyses at the country level, but countryspecific cost structures, epidemiological needs, and national priorities will generally lead to definitions of EUHC that differ from country to country and from the model in this Review. DCP3 is particularly relevant as achievement of EUHC relies increasingly on greater domestic finance, with global developmental assistance in health focusing more on global public goods. In addition to assessing effects on mortality, DCP3 looked at outcomes of EUHC not encompassed by the disability-adjusted life-year metric and related cost-effectiveness analyses. The other objectives included financial protection (potentially better provided upstream by keeping people out of the hospital rather than downstream by paying their hospital bills for them), stillbirths averted, palliative care, contraception, and child physical and intellectual growth. The first $\mathbf{1 0 0 0}$ days after conception are highly important for child development, but the next 7000 days are likewise important and often neglected.

\section{Introduction}

In 1993, the World Bank published Disease Control Priorities in Developing Countries (DCP1), an attempt to systematically assess value for money (cost-effectiveness) of interventions that would address the major sources of disease burden in low-income and middle-income countries (LMICs). ${ }^{1}$ One motivation for DCP1 was to identify reasonable responses in highly resourceconstrained environments to the growing burden of noncommunicable disease and of HIV/AIDS in LMICs. The World Bank had highlighted the already substantial problem of non-communicable diseases in country studies for Malaysia ${ }^{2}$ and China $^{3}$ and in a Shattuck Lecture. ${ }^{4}$ Mexican scholars pointed to the rapid growth of non-communicable diseases in Mexico and introduced the concept of a protracted epidemiological transition involving a dual burden of non-communicable diseases combined with significant lingering problems of infectious disease. ${ }^{5,6}$ The dual burden paradigm remains valid to this day. The World Bank's first (and only) World Development Report about health provided the first assessment of the global burden of disease, an assessment that underlined the importance of non-communicable diseases, which was consistent with subsequent assessments of global disease burden. It then drew heavily on findings from DCP1 to conclude that a number of specific interventions against non-communicable diseases (including tobacco control and multidrug
Published Online November 24, 2017 http://dx.doi.org/10.1016 S0140-6736(17)32906-9 ${ }^{*}$ Contributed equally University of California, San Francisco, San Francisco, CA, USA (Prof DT Jamison PhD, Prof HT Debas MD, Prof J Peabody MD, Prof J Sepúlveda MD) University of Washington, Seattle, WA, USA (Prof A Alwan MD, Prof C N Mock MD D Watkins MD, E Brouwer MPH, K Danforth MPH, Prof K K Holmes MD, ( Levin PhD); RTI International, Seattle, WA, USA (R Nugent PhD); World Bank Group, Washington, DC, USA (O Adeyi DrPH, A Measham MD); Stanford University, Stanford, CA, USA (S Anand MD, Prof M Cullen MD); Harvard T. H. Chan School of Public Health, Boston, MA, USA (Prof R Atun FFPHM, Prof B R Bloom PhD, Prof A Gawande MD, M E Kruk MD, S Verguet PhD); University of California, Berkeley, Berkeley, CA, USA (Prof S Bertozzi MD, Z Olson MA Prof K R Smith PhD); Aga Khan University, Karachi, Pakistan (Prof Z Bhutta PhD); Harvard Medical School, Boston, MA, USA (A Binagwaho MD, Prof A Gawande, T Gaziano MD, EL Krakauer MD, Prof $V$ Patel PhD); Johns Hopkins University Bloomberg School of Public Health, Baltimore, MD, USA (Prof R Black PhD, NWalker PhD); National Treasury of South Africa, Cape Town, South Africa (M Blecher MD); The Bill \& Melinda Gates Foundation, London, UK (D A P Bundy PhD), 
The Bill \& Melinda Gates Foundation, Seattle, WA, USA (D G Walker PhD); World Health Organization Regional Office for Europe, Copenhagen, Denmark (D Chisholm PhD); World Health Organization,

Geneva, Switzerland

(A Cieza PhD, T Dua MD, J-A Mills MIPH, T Reynolds MD);

University of Kelaniya,

Kelaniya, Sri Lanka

(Prof N de Silva PhD); Kwame Nkrumah University of Science and Technology, Kumasi, Ghana (Prof P Donkor MD); Center for Global Health, National Cancer Institute, Bethesda, MD, USA (Prof K A Fleming DPhil); University of Oxford, Oxford, UK (Prof K A Fleming,

T Ord DPhil); Metabiota,

San Francisco, CA, USA (M Gallivan MPH, N Madhav MSPH,

B Oppenheim PhD); Universidad Peruana Cayetano Heredia, Lima, Peru (Prof P J Garcia MD); Brigham and Women's Hospital, Boston, MA, USA (Prof A Gawande, T Gaziano); Fogarty International Center,

US National Institutes of Health, Bethesda, MD, USA (R Glass MD); Center for Global Development, Washington, DC, USA (A Glassman MSc); University of the

Witwatersrand, Johannesburg, South Africa (G Gray MBBCh, Prof STollman PhD); International Clinical Epidemiology Network, New Delhi, India

(Prof D Habte MD); University of Waterloo, Waterloo, ON, Canada (Prof S Horton PhD); UNICEF, New York, NY, USA (G Hutton PhD); University of Toronto, Toronto, ON, Canada (Prof PJha DPhil, H Gelband MHS); University of Miami, Miami, FL, USA (Prof F M Knaul PhD); Makerere University Medical School, Kampala, Uganda

(O Kobusingye MMed); University of Cambridge, Cambridge, UK

(Prof P Lachmann FMedSci); Center for Disease Dynamics,

Economics, and Policy,

Washington, DC, USA (R Laxminarayan PhD); University of Malaya, Kuala Lumpur, Malaysia (Prof L M Looi MD); Princeton, University, Princeton, NJ, USA (Prof A Mahmoud MD, J Qi MS); University Yaoundé I, Yaoundé, secondary prevention of vascular disease) were attractive even in environments where substantial burdens of infection and insufficient dietary intake remained. ${ }^{7.8}$ The World Development Report also pointed to DCP1's finding that opportunities remained to reduce enormously the burden of child mortality and other mortality from these infections. ${ }^{9}$

The second edition of Disease Control Priorities (DCP2), published in 2006, updated and extended DCP1 most notably by explicit consideration of the implications for health systems of expanded coverage of high-priority interventions. ${ }^{10}$ One important linkage to health systems was through examination of selected platforms for delivering logistically related interventions that might be addressing quite heterogeneous sets of problems. Platforms often provide a more natural unit for investment (and for estimating costs) than do individual interventions. Analysis of the costs of providing platforms (and of health improvements they can generate in a given epidemiological environment) can thus help guide health-system investments and development. One example of a platform (within the larger platform of first-level hospital) is the surgery service. A heterogeneous set of conditions is addressed by surgical equipment and surgically trained staff. Both Disease Control Priorities, 3rd edition (DCP3), and WHO's major investment case for health continue to use platforms and their associated costs as important organising concepts. ${ }^{11}$ The DCP3 remit did not include assessment of the impact of DCP1 and DCP2 (although the Bill \& Melinda Gates Foundation has commissioned such a review, emphasising DCP2 and early output from DCP3).

The focus of DCP3 has been on the content of a benefits package. DCP3 does not address two important dimensions of finance-the role of private finance and whether public finance should focus on the poor or be universal. That said, our modelling of the costs and consequences of benefits packages assume universal coverage and low or zero payment at point of service. Our costing estimates include, implicitly, the costs of personnel training and system strengthening, but addressing how to develop personnel and system was beyond the remit of the DCP3.

In this Review, we convey the main findings of DCP3 and, in particular, the conclusions concerning

\section{Panel 1: Key messages from Disease Control Priorities, 3rd edition (DCP3)}

1 DCP3 has found it useful to organise interventions into 21 essential packages that group the interventions relevant to particular professional communities. Each package can contain both intersectoral interventions and health-system interventions. Specific findings from packages point to the attractiveness of widely available surgical capacity, the value of meeting unmet demand for contraception, the potential of a multipronged approach to air pollution, and the importance of maintaining investment in child health and development far beyond the first 1000 days of a child's life.

2 Interventions were selected for packages by a systematic process using criteria of value for money, burden addressed, and implementation feasibility. Collectively, the 218 selected health-system interventions are defined to constitute essential universal health coverage (EUHC). A subset of 108 of these interventions, selected using more stringent criteria, are suggested as a highest priority package (HPP), constituting an important first step on the path to EUHC. Five platforms (population based, community level, health centre, first-level hospital, and referral hospital) provide the delivery base for EUHC. The specific interventions selected for the HPP and for EUHC, and the definitions of platforms and packages, are necessarily quite generic. Every country's definitions and selections will differ from these and from each other's. Nonetheless, we view DCP3's selections to be a potentially useful model list and a starting point for what are appropriately country-specific assessments. The package and EUHC concepts are new in DCP3 and are set up to be easily adapted to country-specific analyses.
3 The costs estimated for the HPP and EUHC are substantial. The HPP is, however, affordable by low-income countries prepared to commit to rapid improvement in population health, and the EUHC is affordable by lower-middle-income countries. Many upper-middle-income countries have yet to achieve EUHC, and they might also find that the EUHC interventions are a useful starting point for discussion.

4 To reduce premature deaths by $40 \%$ by 2030 (known as $40 \times 30$ ) is a goal for mortality reduction closely mirroring the quantitative content of the Sustainable Development Goal 3. Our calculations suggest that low-income countries implementing HPP and lower-middle-income countries implementing EUHC by 2030 will make substantial progress toward this $40 \times 30$ target but are likely to fall short (unless there is an unexpectedly substantial intersectoral action to raise excise taxes on tobacco and adopt other fiscal interventions to reduce behavioural and environmental risk factors for non-communicable diseases).

5 DCP3 has shown that it is possible to identify the main sources of health-related financial risk and impoverishment, to estimate the value of risk reduction, and to use a new method developed for DCP3, the extended cost-effectiveness analysis, to help achieve efficiency in purchase of financial risk reduction. This concern for efficiency in (government) purchase of financial protection is new in DCP3, but DCP3 has made only a beginning in applying these methods. Much remains to be done.

6 In addition to the aggregate conclusions of DCP3, each volume provides rich detail on policy options and priorities. This granularity in the volumes makes them of use to the implementation level of ministries as well as the policy level. 
intersectoral policy priorities and essential universal health coverage. Beyond informing policy discourse, the granularity of analysis reported in DCP3's nine volumes is intended to serve officials within ministries at the implementation level. Beginning with DCP3 volume 1, on essential surgery, the first eight volumes of DCP3 (and related overviews of six of them in The Lancet) were published between 2015 and 2017. The final volume, with cross-cutting and synthesising chapters, will be published in early 2018. DCP3's key messages are summarised in panel 1, and the DCP3's nine volumes and their editors are listed in panel 2 .

The division between intersectoral policies and health sector policies in DCP3's analyses and examples of the risk factors and conditions that the policies address are shown in figure 1. Importantly the DCP3 structure views the role of intersectoral action to be reduction of behavioural and environmental risks, which themselves affect the level of physiological risks and health outcomes directly. The health sector's role in reducing behavioural and environmental risk is viewed as modest-rather, the health sector's main role is in reducing (some of) the physiological risk factors and reducing the duration and severity of health conditions and their sequelae. Appropriate health sector policies also offer the potential for reducing health-related financial risks in a population.

DCP3 has four major objectives that go beyond previous editions. First, DCP3 addresses explicitly the financial risk protection and poverty reduction objective of health systems as well as provision of contraception, reduction in stillbirths, palliative care, and enhancement of the physical and cognitive development of children. Standard health metrics such as quality-adjusted life-years and disabilityadjusted life-years usually do not address these other objectives of health systems, and DCP3 has endeavoured to be explicit about them and their importance. Second, DCP3 devotes systematic attention to disease prevention and the intersectoral determinants of health. Third, DCP3 organises interventions into 21 essential packages that reflect professional communities (panel 3). DCP3 defines a concept of essential universal health coverage (EUHC) in terms of the health-systems components of the 21 essential packages and further identifies a subset of EUHC termed the highest priority package (HPP) that can potentially be afforded by low-income countries and offers the most potential achievement (given limited resources) of health, financial protection, and other objectives. Finally, for both EUHC and HPP, DCP3 provides estimates (for lowincome and for lower-middle-income countries) of the magnitude of their effect on mortality and of their incremental (ie, required expenditure above current levels) and total costs in 2030. In addition to these new elements, DCP3 updates the efforts of DCP1 and DCP2 to assemble and interpret the scientific literature on economic evaluation of health interventions.

Here we introduce the substantive topics addressed by DCP3 and relay our main conclusions. First, we briefly
Panel 2: Nine volumes of Disease Control Priorities, 3rd edition (DCP3)

The World Bank is publishing DCP3 between 2015 and 2018. By contrast with the single (very large) volume formats of DCP1 and DCP2, DCP3 appears in nine small and topical volumes, each with its own editors. Coordination between volumes has been provided by seven series editors, Dean T Jamison, Rachel Nugent, Hellen Gelband, Susan Horton, Prabhat Jha, Ramanan Laxminarayan, and Charles N Mock. The topics and editors of the individual volumes are listed below:

\section{5}

Volume 1: Essential surgery

(edited by Haile T Debas, Peter Donkor, Atul Gawande, Dean T Jamison, Margaret E Kruk, and Charles N Mock, with a foreword by Paul Farmer)

Volume 3: Cancer

(edited by Hellen Gelband, Prabhat Jha, Rengaswamy Sankaranarayanan, and Susan Horton, with a foreword by Amartya Sen)

Volume 4: Mental, neurological, and substance use disorders (edited by Vikram Patel, Dan Chisholm, Tarun Dua, Ramanan Laxminarayan, and María Elena Medina-Mora, with a foreword by Agnes Binagwaho)

\section{6}

Volume 2: Reproductive, maternal, newborn, and child health

(edited by Robert E Black, Ramanan Laxminarayan, Marleen Temmerman, and Neff Walker, with a foreword by Flavia Bustreo)

\section{7}

Volume 5: Cardiovascular, respiratory, and related disorders

(edited by Dorairaj Prabhakaran, Shuchi Anand, Thomas Gaziano, Jean Claude Mbanya, Yangfeng Wu, and Rachel Nugent, with a foreword by K Srinath Reddy)

Volume 6: Major infectious diseases

(edited by King K Holmes, Stefano Bertozzi, Barry R Bloom, and Prabhat Jha, with a foreword by Peter Piot)

Volume 7: Injury prevention and environmental health

(edited by Charles N Mock, Rachel Nugent, Olive Kobusingye, and Kirk R Smith, with a foreword by Ala Alwan)

Volume 8: Child and adolescent health and development (edited by Donald A P Bundy, Nilanthi de Silva, Susan Horton, Dean T Jamison, and George ( Patton, with a foreword by Gordon Brown)

\section{8}

Volume 9: Disease control priorities: improving health and reducing poverty (edited by Dean T Jamison, Hellen Gelband, Susan Horton, Prabhat Jha, Ramanan Laxminarayan, Charles N Mock, and Rachel Nugent, with a foreword by Bill and Melinda Gates and an introduction by Lawrence H Summers)

describe the context in which DCP3's analyses have been undertaken.

\section{Context}

Five considerations set the context for DCP3. The first four were the 20th century revolution in human health, the scientific underpinnings of that revolution, the high estimated returns to (carefully chosen) health investments, and the increasing implementation of universal health coverage (UHC) as a practical goal for domestic finance of health systems. Skolnik ${ }^{12}$ provides further discussion of
Cameroon (Prof J C Mbanya MD); National Institute of Psychiatry de la Fuente Muniz, Mexico City, Mexico (M E Medina-Mora PhD); Praxis Social Impact Consulting, Washington, DC, USA (C Medlin PhD); London School of Hygiene \& Tropical Medicine, London, UK (Prof A Mills PhD, Prof D Prabhakaran MD); University of the Philippines, 


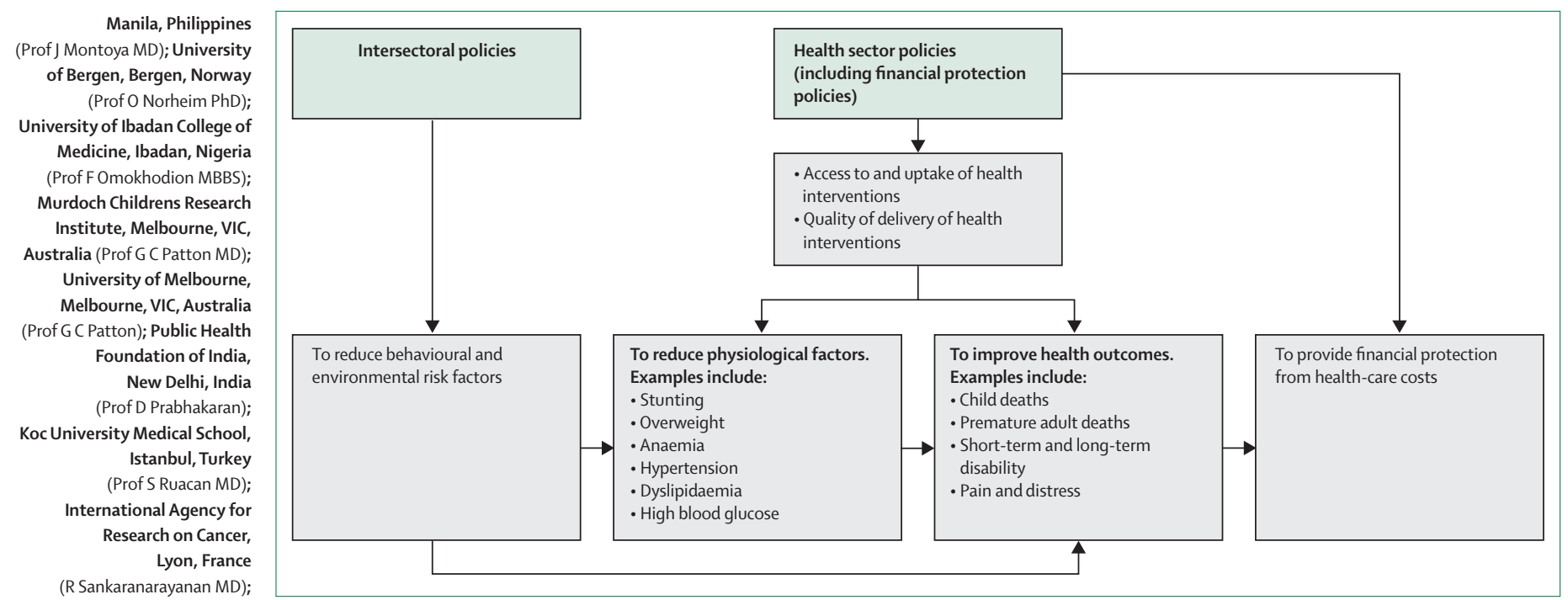
USA (R Skolnik MPA); Aga Khan University East Africa, Nairobi, Kenya (Prof M Temmerman MD); The George Institute for Global

Health at Peking University Health Science Center, Beijing,

China (Prof Y Wu MD); and China National Health Development Research Center,

Beijing, China (K Zhao MD)

Correspondence to: Prof Dean T Jamison, University of California, San Francisco Global Health Sciences, San Francisco, CA 94158, USA djamison@uw.edu

Figure 1: Policies for heath

It is important to recognise that policies affecting health-sector finance, and hence the functioning and success of the health sector, often originate outside the health sector (eg, in social security agencies).

\section{Panel 3: Clusters of essential packages*}

\section{Age-related cluster (packages 1-5)}

1 Maternal and newborn health

2 Child health

3 School-age health and development

4 Adolescent health and development

5 Reproductive health and contraception

Infectious diseases cluster (packages 6-10)

6 HIV and sexually transmitted infections

7 Tuberculosis

8 Malaria and adult febrile illness

9 Neglected tropical diseases

10 Pandemic and emergency preparedness

Non-communicable disease and injury cluster (packages 11-17)

11 Cardiovascular, respiratory, and related disorders

12 Cancer

13 Mental, neurological, and substance use disorders

14 Musculoskeletal disorders

15 Congenital and genetic disorders

16 Injury prevention

17 Environmental improvements

Health services cluster (packages 18-21)

18 Surgery

19 Rehabilitation

20 Palliative care and pain control

21 Pathology

*Country applications will define packages in a way relevant to local policy. For example, the structure here distributes urgent interventions across packages, but in many contexts defining an emergency care package might prove more relevant. these four issues. A fifth consideration concerns evolution in thinking about the international dimension of health finance-development assistance for health broadly defined. This context points to the importance of funding health systems adequately (a record of remarkable success and high economic returns) and of getting high value for money from the resources spent.

Chile exemplifies the two key elements of the 20th century revolution in human health. One is the sheer magnitude of improvement. As recently as in 1910, life expectancy was less than 32 years. By 2010 life expectancy exceeded 78 years. Second, time has narrowed cross-country differences. In 1910, world leaders (eg, Australia and New Zealand) had life expectancies almost 30 years higher than in Chile, but that gap had narrowed by 2010 to about 4 years. The magnitude of Chile's success has been unusual, but the broad story it conveys is not. That said, very substantial gaps remain in health between countries, and a major purpose of DCP3 is to point very specifically to approaches to closing these gaps.

Nurturing continuation of scientific investment remains a policy priority, as was extensively discussed in DCP2. DCP3 has devoted less attention to research and development than did DCP2, in part because of the coverage there. ${ }^{13-17}$ Although research and development are discussed in several places, ${ }^{18,19}$ a careful mining of DCP3 for its implications for basic research and for new product development remains to be done. Income growth in the past century and past decades has contributed to increased life expectancy as have, to a greater extent, improvements in education levels and improved tools. But the availability of new tools and their rate of uptake appear to be the dominant sources of mortality decline. ${ }^{20}$ 
Valuation of mortality decline (or health change more generally) is excluded from the global system of national income and product accounts. Economists have nonetheless expended substantial effort on tracing the effect of health improvements on household and national income and on assessing the economic value of the small reductions in mortality risk that have occurred year by year. The Lancet Commission on Investing in $\mathrm{Health}^{2}$ and the Copenhagen Consensus ${ }^{22}$ reviewed and extended the literature on the value of health improvements, pointing to high returns indeed.

As national incomes increase, countries typically increase the percentage of national income devoted to health. Equally significantly, they increase the proportion of health expenditures that are prepaid, usually through public or publicly mandated finance. Tedros Ghebreyesus, WHO's new Director-General, has reaffirmed WHO's commitment to UHC and to the use of evidence and data in support of achieving that goal. ${ }^{23}$ The Lancet Commission on Investing in Health ${ }^{21}$ advocated variants on a pathway toward UHC (progressive universalism) that emphasised two initial priorities for action: universal coverage of publicly financed interventions and reductions of user payments at the point of service (for those interventions) to very low levels. An increased emphasis on domestic financing for UHC has led to the need for greater initial selectivity in the range of interventions to be financed in UHC packages. It should be noted that in many countries public finance has been successfully combined with private sector provision. Many considerations will influence national choices of how benefits packages will evolve over time. DCP3 is intended to contribute to the deliberation of these choices. A recent report from the Center for Global Development ${ }^{24}$ provides valuable discussion of the considerations that might reasonably go into development of a benefits package.

With substantial income growth in (most) LMICs and an increasing number of countries committed to public finance of UHC, the role of development assistance is being reexamined. ${ }^{21,25}$ As the World Bank and others have long argued, finance ministers will often reduce domestic allocations to sectors receiving substantial foreign aid. The challenge to those concerned with aid effectiveness thus becomes one of identifying and supporting important activities that national finance ministries will plausibly under-finance (such as research and development, pandemic preparedness, and control of antimicrobial resistance). In a recent assessment, support for these global public goods was found to constitute more than $20 \%$ of development assistance for health broadly defined; the authors make the case that percentage should steadily increase over time. ${ }^{26}$ This view of development assistance has clear implications for construction of model benefits packages for domestic finance: other things equal, domestic finance should emphasise services having national importance and leave the finance of global (or regional) public goods to international finance. The DCP3 HPP does not include finance of pandemic preparedness for just this reason.

\section{Packages, platforms, and policies}

DCP3 defines packages of interventions as conceptually related interventions (eg, those dealing with cardiovascular disease or reproductive health or surgery). An objective of each DCP3 volume was to define one or more essential packages and the interventions in that package that might be acquired at an early stage on the pathway to UHC. The essential packages comprise interventions that provide value for money, are implementable, and address substantial needs. This matrix structure (with packages as the rows, intersectoral policies and healthsystems platforms as the columns, and interventions as the entries) is novel to DCP3. It remains to be seen whether this structure is helpful, but the DCP3 authors, at least, have found it so.

Platforms are defined as logistically related delivery channels. Panel 3 shows how DCP3 groups EUHC interventions within packages that can be carried on different types of platforms.

The temporal character of interventions is very important for health-system development. Patients requiring non-urgent but substantial intervention (eg, repair of cleft lips and palates) can be accumulated over space and time enabling the efficiencies of high volume in service delivery. In DCP3, urgent interventions are dispersed across packages. They could, as plausibly, be grouped into a package of emergency care. Urgent interventions, which include a large fraction of essential surgical interventions, are ideally available at all times and close to where patients live, with important implications for dispersal of relevant platforms and integration of different services. ${ }^{27}$ Non-urgent but continuing interventions to address chronic conditions (eg, secondary prevention of vascular disease or antiretroviral therapy for HIV-positive individuals) is a big and quite distinct challenge. One new product of DCP3 has been to explicitly categorise all essential interventions into one of these three temporal categories and to draw relevant lessons, including concerning cost, for health systems.

In total, 71 distinct intersectoral policies (fiscal, regulatory, infrastructural, and informational) for reducing behavioural and environmental risk were identified (appendix), and 29 of these were identified as candidates for early implementation. In addition to intersectoral policies, DCP3 selectively reviews policies that affect the uptake of health sector interventions (eg, conditional cash transfers) and the quality with which they are delivered..$^{28}$

\section{The DCP3 approach}

We have thoroughly updated findings from DCP2 on costs, effectiveness, and cost-effectiveness. The literature 
Panel 4: Evidence for policy: from research findings to policy parameters

Analysis in Disease Control Priorities, 3rd edition (DCP3) proceeds by attempting to make the best use of the evidence available for informing important decisions rather than exclusively using what ideally generated evidence has to say. ${ }^{30}$ The distinction is important. An example is illustrative: quite good evidence is available on the effect of vector control on malaria mortality in specific environments; likewise there is strong evidence concerning treatment efficacy, but very little evidence exists on whether vector control and treatment are substitutes, complements, or additive in reducing mortality, yet this is the important question for policy.

Inevitably imperfectly, our task in the Disease Control Priorities series, beginning with the 1st edition, has been to combine the (sometimes) good science about unidimensional intervention in very specific locales with informed judgment to reach reasonable conclusions about the effect of intervention mixes in diverse environments. To put this slightly differently, the parameters required for assessing policy differ, often substantially, from what has been addressed (so far) in the scientific literature. The transition from research findings to policy parameters requires judgment to complement the research and, often, a consideration of underlying mechanisms (eg, use of incentives) that might suggest generalisability. ${ }^{31}$

In particular, four types of judgments were often needed in the course of DCP3 to make the transition from research findings to evidence for policy.

\section{Similar interventions}

Assume we have evidence that intervention $A$ is effective, and we believe intervention $B$ is quite similar (eg, two lipid-lowering drugs). We use judgment to infer that intervention $B$ is (or perhaps is not) also effective.

\section{Combined interventions}

As in the malaria example above, assume that evidence shows interventions $A$ and $B$ are both effective. What about the combination of interventions $A$ and $B$ ? Hard evidence on combinations is far more rare than evidence on individual interventions.

\section{Changed settings}

We have strong evidence that antimalarial bednets reduce all-cause child mortality when mosquitoes bite indoors at night, at moderate intensity. Although the available evidence concludes that bednets were effective where evaluated, other biological considerations suggest that evidence be rejected in an environment with very high biting intensity. Economists have discussed this point in the context of external validity. Ozler provides a clear overview. ${ }^{32}$

\section{Trait-treatment interactions}

Finally, patient characteristics might differ. Measles immunisation in healthy child populations might have been shown to have no effect on mortality. Generalising that finding to a population with different traits (eg, undernourished or sickly children) might (and in this case would) generate an unfortunate false negative.

Evidence can be weak. Or, as in the examples above, evidence can be strong but only partially relevant. Weak evidence for effectiveness, or partially relevant evidence for effectiveness, is often likewise weak evidence for lack of effectiveness. Interpreting weak evidence as grounds for rejecting an intervention could generate false negatives that cost lives. The attempt in DCP3 has been to unashamedly combine evidence with informed judgment to judiciously balance false positives and false negatives.

provides much of specific interest, but formulation of policy, when informed by evidence at all, requires expert judgment to fill extensive gaps in the economic evaluation literature. The question to be addressed is one of how to construct a cost-constrained benefit package for UHC. Recent analyses have provided thoughtful discussion of considerations involved, including human rights. ${ }^{24,29}$ The DCP3 approach draws heavily on this prior work but with more emphasis on non-health outcomes of health systems. In this section we discuss the DCP3 approach that led both to a 3P approach (packages, policies, and platforms) and to the specific content for intersectoral policy and for the packages and platforms. The methods are described more fully in the tables.

Using research (or other) evidence to guide policy is most simply done when randomised controlled trials of the relevant intervention (mix) have been undertaken on the population of interest in the appropriate ecological setting. Even in high-income countries such strong evidence is rarely available. In lower-income environments the evidence quality problem is compounded. As always, evidence must be used to help decision makers avoid adopting interventions that do not work in a given context and avoid rejecting those that do (panel 4).

The methods and findings of DCP3's approaches to economic evaluation appear in three separate chapters of DCP3's concluding volume: one chapter on costeffectiveness analysis, ${ }^{33}$ one on benefit-cost analysis, ${ }^{34}$ and one on extended cost-effectiveness analysis..$^{35} \mathrm{~A}$ high-level overview of DCP3's economic methods and findings appears in the appendix. In populations without access to health insurance or prepaid care, medical expenses that are high relative to income can be impoverishing. In most of the literature on medical impoverishment, the medical conditions responsible for this impoverishment are not identified. Essue and colleagues ${ }^{36}$ point to where specific causes of medical impoverishment are known, which is obviously a central point for construction of benefits packages.

Although multiple studies document the overall magnitude of medical impoverishment, most economic assessments of health interventions and their finance have not adequately addressed the important question of efficiency in the purchase of financial protection. In work undertaken for DCP3, extended cost-effectiveness analysis was developed to explicitly include financial protection (and equity) in economic assessment of health interventions. ${ }^{37}$

Editors of DCP3's first eight volumes and authors of specific chapters in volume 9 (on rehabilitation, ${ }^{38}$ on pathology, ${ }^{39}$ on palliative care $^{40}$ and pandemic preparedness ${ }^{41}$ ) constructed the 21 essential packages listed in panel 3. The authors of this Review then consolidated those policies and formats into a common level of aggregation and a common structure (eg, screening was not considered an intervention by itself but only in conjunction with the indicated response). This generated a set of harmonised essential packages (the originals appear as appendices to the first chapter of DCP3; the second and third chapter provide a full discussion of methods ${ }^{42-44}$ ). Several interventions appear in more than one package, but the final lists of 71 intersectoral 
policies and 218 EUHC interventions remove this duplication. A consequence is that the cost of EUHC is less than the sum of the costs of the packages within it.

\section{Intersectoral policies for health}

15 of DCP3's 21 essential packages contained a total of 71 intersectoral policies. These policies fall into four broad categories: (1) taxes and subsidies (15 of 71 intersectoral policies); regulations and related enforcement mechanisms (38 of 71 intersectoral policies); built environment (11 of 71 intersectoral policies); and informational (seven of 71 intersectoral policies). A complete listing of the 71 intersectoral policies is available in the appendix. These policies are designed to reduce the population level of behavioural and environmental risk factors (tobacco and alcohol use, air pollution, micronutrient deficiencies in the diet, unsafe sexual behaviour, excessive sugar consumption, and others; figure 1). Watkins and colleagues $^{44}$ provide a thorough overview of DCP3's findings on intersectoral policy. Here we exemplify our approach with several of DCP3's findings

First, at initially low levels of income, the levels of many risk factors rise with income, thereby creating headwinds against which the health sector policy must proceed ${ }^{45}$ but are least potentially countered by sound policy. We identified 29 out of 71 intersectoral policies to be well worth considering for early adoption.

Second, for important categories of risk, such as pollution and transport risks, multiple sources for the risk exist, each of which is addressed through different modalities. Rather than a clear set of first priorities, there are multiple country or site-specific actions to be taken. Perhaps the single most important point to note is that the success of many high-income countries in reducing these risks to very low levels points to the great potential that these multiple policies can have for dealing, in particular, with air pollution and road traffic injuries.

Third, potentially important areas of dietary risk remain unaddressed by the policies identified in DCP3. These areas concern the macronutrients-carbohydrates, fats, and proteins. The most recent assessment of risk factors for the Global Burden of Disease (GBD) points to the reason for limited policy guidance. ${ }^{46}$ The GBD lists 11 risk factors in the category of child and maternal malnutrition, but only two of these risk factors are dietary (both concern breastfeeding). The other risk factors, such as child wasting, are what we label physiological (figure 1) and are consequences of diet and disease history. GBD lists 15 risk factors for non-communicable disease, all of them dietary (eg, diets low in fruits). These dietary risk factors do provide directions for intersectoral policy, ${ }^{47}$ and relevant policies are included in the DCP3 list of 71 intersectoral policies. Yet empirical studies to guide major macronutrient policy directions, for example toward reducing intake of carbohydrates or fats, are only beginning to appear. ${ }^{48,49}$ Much policy interest (eg, taxes) would rely on this missing information.

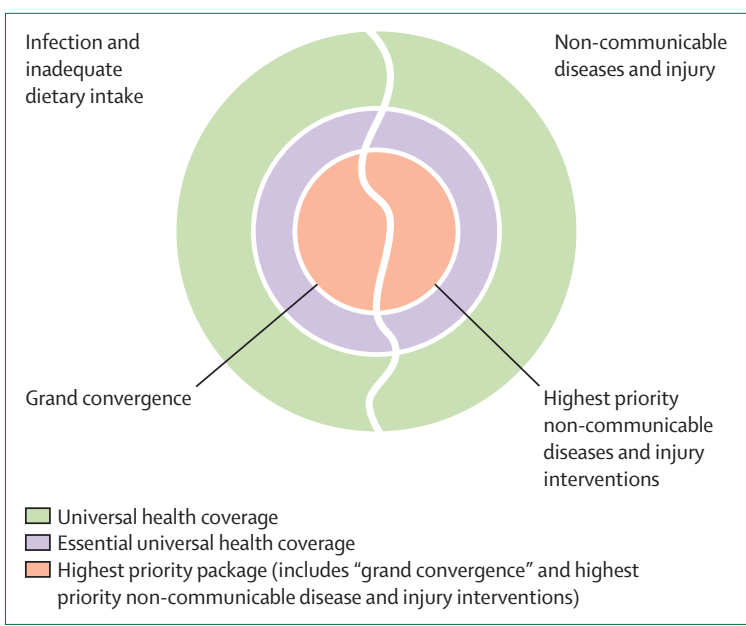

Figure 2: Essential universal health coverage and the highest priority package The grand convergence agenda for reducing child and infectious disease mortality was advanced by the Lancet Commission on Investing in Health. ${ }^{21}$

A fourth point is that existing analyses of genetic risk and of medical intervention risk remain to be included in disease burden studies. ${ }^{46}$ Although genetics cannot be ethically changed, genetic information can be an important guide to intervention. Medical risks can be quite substantial as Atul Gawande and Tom Weiser ${ }^{50}$ document in the DCP3 chapter on quality of surgical care. Some medical risks are side-effects of inherent risks from intervention, some are medical error, and some result from inadequate resources available to the provider. We discuss genetic risk and intervention risk along with other risk factors although, clearly, the health system itself provides the compensatory interventions.

A fifth point is that fiscal policies (finance ministry policies) are important. Discussion of these policies has most prominently involved large increases in excise taxation of tobacco, with emerging evidence on taxation of alcohol and sugar-sweetened beverages. But the possibilities for taxation extend to sugar production and imports, fossil fuels (or carbon), and industrial or vehicle emissions. Also of importance is reducing expensive subsidies that now exist on fossil fuels and, often, on unhealthy food production or unhealthy child dietary supplements. Although health improvement might be only one of several objectives for lowering subsidies, it is an important one. The scientific literature on the health potential for removing subsidies is limited. But the sheer magnitude of some of these subsidies, as the International Monetary Fund has stressed, points to the value of careful further analysis. In all likelihood, the finance ministry is the most important ministry (after health) for improving population health. And many (not all) of the measures a finance ministry can take would enhance public sector revenue.

\section{Essential universal health coverage}

At the heart of DCP3 was a review of available evidence on health-sector interventions' costs, effectiveness, 


\begin{tabular}{|c|c|c|c|c|c|c|c|c|}
\hline & \multicolumn{4}{|c|}{ Low-income countries } & \multicolumn{4}{|c|}{ Lower-middle-income countries } \\
\hline & $\begin{array}{l}\text { Projected } \\
\text { number of } \\
\text { premature } \\
\text { deaths, } 2030 \\
\text { (millions)* }^{*}\end{array}$ & $\begin{array}{l}40 \times 30 \\
\text { reduction } \\
\text { target } \\
\text { (millions) } \dagger\end{array}$ & $\begin{array}{l}\text { Expected } \\
\text { reduction in } \\
\text { premature } \\
\text { deaths from } \\
\text { HPP (millions) }\end{array}$ & $\begin{array}{l}\text { Expected } \\
\text { reduction in } \\
\text { premature } \\
\text { deaths from } \\
\text { EUHC (millions) }\end{array}$ & $\begin{array}{l}\text { Projected } \\
\text { number of } \\
\text { premature } \\
\text { deaths, } 2030 \\
\text { (millions) }\end{array}$ & $\begin{array}{l}40 \times 30 \\
\text { reduction } \\
\text { target } \\
\text { (millions) } \dagger\end{array}$ & $\begin{array}{l}\text { Expected } \\
\text { reduction in } \\
\text { premature } \\
\text { deaths from HPP } \\
\text { (millions) }\end{array}$ & $\begin{array}{l}\text { Expected } \\
\text { reduction in } \\
\text { premature } \\
\text { deaths from } \\
\text { EUHC (millions) }\end{array}$ \\
\hline \multicolumn{9}{|l|}{ Age (years) } \\
\hline $0-4$ & $2 \cdot 2$ & $1 \cdot 5$ & 0.62 & $0 \cdot 77$ & $3 \cdot 3$ & $2 \cdot 2$ & $1 \cdot 1$ & $1 \cdot 3$ \\
\hline $5-69$ & $5 \cdot 2$ & 1.5 & 0.99 & $1 \cdot 2$ & 14 & $4 \cdot 8$ & $2 \cdot 2$ & $2 \cdot 9$ \\
\hline $0-69$ & $7 \cdot 4$ & $3 \cdot 0$ & 1.6 & $2 \cdot 0$ & 17 & $7 \cdot 0$ & $3 \cdot 2$ & $4 \cdot 2$ \\
\hline \multicolumn{9}{|c|}{ By cause (age $\geq 5$ years) $\ddagger$} \\
\hline Group 1 & 1.9 & 0.76 & 0.59 & 0.65 & $3 \cdot 2$ & $1 \cdot 5$ & 0.85 & 0.94 \\
\hline Tuberculosis & 0.34 & 0.22 & 0.11 & 0.13 & 0.90 & 0.60 & 0.29 & 0.35 \\
\hline HIV/AIDS & 0.44 & 0.29 & 0.18 & $0 \cdot 20$ & 0.48 & 0.32 & 0.23 & 0.26 \\
\hline Malaria & 0.087 & 0.058 & 0.051 & 0.051 & 0.055 & 0.037 & 0.026 & 0.026 \\
\hline $\begin{array}{l}\text { Maternal } \\
\text { conditions }\end{array}$ & $0 \cdot 17$ & $0 \cdot 11$ & 0.075 & 0.086 & 0.20 & $0 \cdot 13$ & 0.079 & 0.092 \\
\hline Other diseases & 0.90 & 0.074 & 0.18 & 0.18 & 1.6 & 0.40 & 0.22 & 0.22 \\
\hline Group 2 & 2.5 & 0.60 & 0.36 & 0.53 & 8.9 & $2 \cdot 7$ & $1 \cdot 3$ & 1.9 \\
\hline Neoplasms & 0.65 & 0.22 & 0.010 & 0.039 & $1 \cdot 8$ & 0.60 & 0.10 & 0.16 \\
\hline $\begin{array}{l}\text { Cardiovascular } \\
\text { diseases }\end{array}$ & 0.93 & 0.31 & 0.24 & 0.36 & $4 \cdot 0$ & $1 \cdot 3$ & 0.89 & $1 \cdot 4$ \\
\hline Other diseases & 0.93 & 0.076 & 0.11 & $0 \cdot 13$ & $3 \cdot 2$ & 0.80 & 0.28 & 0.35 \\
\hline Group 3 & 0.77 & $0 \cdot 13$ & 0.043 & 0.060 & $2 \cdot 0$ & 0.54 & 0.070 & 0.10 \\
\hline Road injuries & 0.25 & 0.085 & 0.032 & 0.046 & 0.57 & 0.19 & 0.048 & 0.069 \\
\hline Other injuries & 0.52 & 0.042 & 0.010 & 0.014 & $1 \cdot 4$ & 0.36 & 0.022 & 0.032 \\
\hline \multicolumn{9}{|c|}{$\begin{array}{l}\text { The cost and diseases structures differ between and within income levels. We illustrate this by considering two income strata, but the analyses reported here can serve only as } \\
\text { a starting point for national and subnational analyses. A premature death is death before age } 70 \text { years. We used the World Bank's income classification of low-income and } \\
\text { lower-middle-income countries. } .^{55} \mathrm{As} \text { a country's income changes, its classification can also change; for example, both Bangladesh and Kenya moved from low-income status } \\
\text { to lower-middle income status after } 2014 \text {. HPP=highest priority package. EUHC=essential universal health coverage. *The UN Population Prospects median population } \\
\text { projection for } 2030^{56} \text { was used to provide the population totals for calculating deaths by age and sex. †A reduction target of } 40 \times 30 \text { is defined as a } 40 \% \text { reduction in } \\
\text { premature deaths by } 2030 \text {, relative to the number that would have occurred had } 2015 \text { mortality persisted to } 2030 \text {. The target specifies a } 40 \% \text { reduction in deaths in } \\
\text { people aged } 0-69 \text { years overall, a two-thirds reduction in under- } 5 \text { deaths and adult deaths from tuberculosis, HIV/AIDS, malaria, and maternal conditions, and a one-third } \\
\text { reduction in deaths from major non-communicable diseases. The quantitative targets above reflect these goals; however, targets for the residual categories (Other diseases } \\
\text { and Other injuries) have been calculated in light of the targets for specific causes of death so that the total number of target deaths in people aged } 5-69 \text { years is sufficient to } \\
\text { meet the } 40 \times 30 \text { target. } \neq W H O \text { 's Global Health Estimates provided the } 2015 \text { cause distributions of deaths for these calculations. }{ }^{54} \text { Sources: Watkins et al (2017) }{ }^{57} \text { and } \\
\text { Watkins et al (in press). }{ }^{43}\end{array}$} \\
\hline
\end{tabular}

implementability, and capacity to deliver significant outcomes. DCP3's nine volumes provide granular overviews of this evidence, and these overviews are directed to the implementation community and the policy community. Chapter 3 of volume 9 provides an integrative overview. $^{43}$ Each of the interventions on DCP3's five platforms are described in the appendix.

A schema of how DCP3 defines EUHC is shown in figure 2. Beyond EUHC is the full range of available, efficacious health-sector interventions or UHC. We estimate the financial requirements of EUHC and the HPP, but would also stress that WHO's notion of UHC emphasises quality of delivery. DCP3 dwells in some length on quality in surgery and in health care more generally. ${ }^{28,50}$ Although no country publicly finances all interventions, many high-income countries come close. Countries lie on a natural continuum of progress toward UHC. Short of EUHC is what DCP3 labels the HPP (the interventions included in the HPP are shown in the appendix). Individual countries' highest priorities will differ from our model list for multiple reasons. That said, the HPP is intended to provide a useful starting point for national or subnational assessments. As with EUHC, DCP3's models provide estimates for the cost and impact of HPP. In Global Health 2035, ${ }^{21}$ the Lancet Commission on Investing in Health pointed to the possibility of a grand convergence, across most countries and in our lifetime, in under-5 mortality and mortality from major infections. Grand convergence within the DCP3 structure is illustrated in figure 2. In the two following subsections, we provide the DCP3 models' estimates of the mortalityreducing consequences and costs of EUHC. Achieving these gains will require substantial investments in health systems. Although the DCP3's costing model includes the cost of such investment, it was beyond the remit of DCP3 to address how to strengthen health systems. Mills and colleagues ${ }^{51}$ provide a valuable overview of the issues in the context of DCP. 
Importantly, EUHC has a platform dealing with population-wide intervention, including intervention directed toward improving doctor practices with antibiotic use or inappropriate polypharmacy. In many cases, whether we denote an intervention to be intersectoral or to be population-wide prevention within the health sector is somewhat arbitrary.

\section{Motality reduction from essential UHC}

Norheim and colleagues ${ }^{52}$ developed a structure, $40 \times 30$, for thinking about mortality reduction objectives in the Sustainable Development Goal 3 (SDG-3). Their starting point was the UN's Population Division (UNDP) projected age distribution of population in 2030, a distribution of deaths by age and cause generated from that age distribution of population, and mortality from 2010. The overall $40 \times 30$ goal was to reduce the calculated number of premature deaths by $40 \%$, where premature death is defined as death before age 70 years. Subgoals were to reduce under- 5 mortality and death from major infectious diseases by two-thirds and deaths from noncommunicable disease and injury by a third. The DCP3 mortality impact model ${ }^{53}$ follows the approach taken by Norheim and colleagues in broad terms but uses updated parameters. National applications of the DCP3 model will result in country-specific calculation and modification of these goals. The model's calculations start with a baseline age distribution of deaths by age and (broad) cause generated from the UNPD's projected age distribution of population and age in 2030 combined with cause-specific mortality from 2015. ${ }^{54}$ It then estimates the effect of EUHC (and HPP) on mortality by assuming that the underlying intervention packages are implemented in the 15 years from 2015 to 2030 (the packages were designed to make this assumption reasonable). The age-specific and cause-specific mortality from counterfactual 2015 are then applied to the UNPD 2030 age distributions to give the age distributions of death by cause estimated to result from implementation of EUHC.

The DCP3 model enables comparison of the EUHC mortality profile to an explicit counterfactual baseline (table 1). Implementation of the HPP in low-income countries could achieve about half of the $40 \times 30$ goal (the estimated reduction in deaths is 1.6 million of the $40 \times 30$ target of 3.0 million). Full implementation of EUHC in lower-middle-income countries could achieve a little more than half of the $40 \times 30$ target of 2.2 million deaths averted in children younger than 5 years. The results for age group 5-69 years fall short of the $40 \times 30$ target of 4.8 million. Estimated deaths averted by EUHC ( 4.2 million) is about three-fifths of the $40 \times 30$ target of $7 \cdot 0$ million.

If we were to assume that both tools and implementation capacity improve between now and 2030 (the Lancet Commission on Investing in Health ${ }^{21}$ made an assumption of a $2 \%$ rate of technical progress

\begin{tabular}{|c|c|c|c|c|}
\hline & \multicolumn{2}{|c|}{ Low-income countries } & \multicolumn{2}{|c|}{ Lower-middle-income countries } \\
\hline & HPP & EUHC & HPP & EUHC \\
\hline Incremental annual $\operatorname{cost}^{*} \dagger$ & $\$ 23$ billion & $\$ 48$ billion & $\$ 82$ billion & $\$ 160$ billion \\
\hline Incremental annual cost per person* & $\$ 26$ & $\$ 53$ & $\$ 31$ & $\$ 61$ \\
\hline Total annual cost & $\$ 38$ billion & $\$ 68$ billion & $\$ 160$ billion & $\$ 280$ billion \\
\hline Total annual cost per person $\dagger$ & $\$ 42$ & $\$ 76$ & $\$ 58$ & $\$ 110$ \\
\hline $\begin{array}{l}\text { Incremental annual cost as a percentage } \\
\text { of current GNI per person** }\end{array}$ & $3 \cdot 1 \%$ & $6 \cdot 4 \%$ & $1.5 \%$ & $2 \cdot 9 \%$ \\
\hline $\begin{array}{l}\text { Total annual cost (as percentage of } \\
\text { GNI per person) } \ddagger\end{array}$ & $5 \cdot 1 \%$ & $9 \cdot 1 \%$ & $2 \cdot 8 \%$ & $5 \cdot 2 \%$ \\
\hline
\end{tabular}

The cost and disease structures differ between and within income levels. We illustrate that by considering two income strata, but the analyses reported here can serve only as a starting point for national and subnational analyses. Lower and upper uncertainty ranges were derived from optimistic and pessimistic cost scenarios (respectively) that were based on variations in key parameters in the costing model. Uncertainty ranges are provided in the appendix. We use the World Bank's 2014 income classification of low-income and lower-middle-income countries..$^{55}$ As a country's income changes its classification can also change; for example, both Bangladesh and Kenya moved from low-income to lower-middle income after 2014. GNI=gross national income. *The 2015 population of low-income countries was 0.90 billion people, whereas the 2015 population for lower-middle-income countries was 2.7 billion people. Incremental annual cost is the estimated cost of going from current to full $(80 \%)$ coverage of the EUHC and HPP interventions. The total annual cost is the incremental cost plus the estimated cost of the current level of coverage assuming the same cost structure for current as for incremental coverage. Estimated costs are inclusive of estimates for (large) health-system strengthening costs and are steady state (or long-term average) costs in that investments to achieve higher levels of coverage and to cover depreciation are included. $¥$ The $2015 \mathrm{GNI}$ per capita of low-income countries was US $\$ 830$. For lower-middle-income countries it was $\$ 2100$. Note that GNI data were only available for countries covering $84 \%$ and $96 \%$ of the population of low-income and lower-middle-income countries, respectively. Data were less likely to be available for poorer countries and fragile states, hence these GNI figures are likely to be an overestimate of income, particularly in the low-income country group. Source: Watkins et al (2017). ${ }^{57}$

Table 2: Total and incremental annual costs of essential universal health coverage (EUHC) and the highest priority package (HPP), 2015 (in US\$[2012])

\begin{tabular}{|c|c|c|c|c|}
\hline & \multicolumn{2}{|c|}{$\begin{array}{l}\text { Low-income } \\
\text { countries }\end{array}$} & \multicolumn{2}{|c|}{$\begin{array}{l}\text { Lower-middle- } \\
\text { income countries }\end{array}$} \\
\hline & HPP & EUHC & HPP & EUHC \\
\hline \multicolumn{5}{|c|}{ Incremental costs by platform (percentage of total) } \\
\hline Population-based & $0.6 \%$ & $2 \cdot 3 \%$ & $0.6 \%$ & $2 \cdot 0 \%$ \\
\hline Community & $18 \%$ & $16 \%$ & $12 \%$ & $14 \%$ \\
\hline Health centre & $50 \%$ & $52 \%$ & $57 \%$ & $52 \%$ \\
\hline First-level hospital & $25 \%$ & $25 \%$ & $22 \%$ & $25 \%$ \\
\hline $\begin{array}{l}\text { Referral and specialty } \\
\text { hospitals }\end{array}$ & $6 \cdot 4 \%$ & $5 \cdot 2 \%$ & $9 \cdot 1 \%$ & $6 \cdot 1 \%$ \\
\hline \multicolumn{5}{|c|}{ Incremental costs by intervention urgency (percentage of total) } \\
\hline Urgent & $35 \%$ & $28 \%$ & $27 \%$ & $24 \%$ \\
\hline Chronic & $41 \%$ & $48 \%$ & $50 \%$ & $52 \%$ \\
\hline Time-bound (non-urgent) & $24 \%$ & $24 \%$ & $23 \%$ & $24 \%$ \\
\hline \multicolumn{5}{|c|}{$\begin{array}{l}\text { The cost and disease structures differ between and within income levels. This is } \\
\text { illustrated by considering two income strata, but the analyses reported here can } \\
\text { serve only as a starting point for national and subnational analyses. } \\
\text { Sources: Watkins et al }(2017)^{57} \text { and Watkins et al (in press). } \text {. }^{43}\end{array}$} \\
\hline \multicolumn{5}{|c|}{$\begin{array}{l}\text { Table 3: Incremental costs of the highest priority package (HPP) and the } \\
\text { essential universal health coverage (EUHC) by platform and by } \\
\text { intervention urgency }\end{array}$} \\
\hline
\end{tabular}

in one of their scenarios), then the reduction in deaths from EUHC could be more substantial than shown in table 1 . Likewise, the reduction in behavioural and environmental risk could be greater than anticipated. Such progress is certainly possible but might be 


\begin{tabular}{|c|c|c|c|}
\hline & $\begin{array}{l}\text { Lancet Commission on Investing in } \\
\text { Health }^{21}\end{array}$ & DCP3 $3^{50,54}$ & WHO $2017^{11}$ \\
\hline Countries included & $\begin{array}{l}34 \text { low-income and three (large) } \\
\text { lower-middle-income countries* }\end{array}$ & 34 low-income and 49 lower-middle-income countries* & $\begin{array}{l}67 \text { low-income, lower-middle, and upper-middle-income } \\
\text { countries individually estimated and then aggregated } \dagger\end{array}$ \\
\hline $\begin{array}{l}\text { Key definitions and } \\
\text { intervention range } \\
\text { covered }\end{array}$ & $\begin{array}{l}\text { Grand convergence interventions lead } \\
\text { to very substantial cross-country } \\
\text { convergence in under-5, maternal, } \\
\text { tuberculosis, malaria, and HIV/AIDS } \\
\text { mortality and in the prevalence of } \\
\text { neglected tropical diseases }\end{array}$ & $\begin{array}{l}21 \text { packages (table } 1 \text { ) identified in terms that include } \\
\text { intersectoral and health sector interventions ( } 72 \text { distinct } \\
\text { intersectoral interventions and } 244 \text { distinct health sector } \\
\text { interventions); EUHC are health sector interventions in the } \\
21 \text { packages (covered in national health accounts and } \\
\text { potentially included in benefits packages); a highest priority } \\
\text { subset of EUHC (HPP) includes a limited range of } \\
\text { interventions against non-communicable diseases, injuries, } \\
\text { and cross-cutting areas such as rehabilitation and palliative } \\
\text { care, in addition to the grand convergence interventions }\end{array}$ & $\begin{array}{l}\text { Investments were modelled for } 16 \text { SDGs, including } 187 \text { health } \\
\text { interventions and a range of health-system strengthening } \\
\text { strategies (the latter of which included investments required to } \\
\text { achieve target levels of health workforce, facilities, and other } \\
\text { health-system building blocks); two scenarios were modelled, } \\
\text { a progress scenario (in which coverage is limited by the absorptive } \\
\text { capacity of current systems to incorporate new interventions), } \\
\text { and an ambitious scenario (in which most countries achieve high } \\
\text { levels of intervention coverage and hence SDG targets) }\end{array}$ \\
\hline $\begin{array}{l}\text { Intersectoral action } \\
\text { for health }\end{array}$ & $\begin{array}{l}\text { Extensive discussion of intersectoral } \\
\text { actions for health but not included in } \\
\text { modelling grand convergence }\end{array}$ & $\begin{array}{l}\text { Intersectoral interventions defined as those typically } \\
\text { managed and financed outside the health sector; each of } \\
\text { the } 21 \text { packages contains the intersectoral interventions } \\
\text { deemed relevant; the costs and effects of intersectoral } \\
\text { action on mortality reduction are not explicitly modelled }\end{array}$ & $\begin{array}{l}\text { WHO } 2017 \text { scenarios include some finance of intersectoral } \\
\text { interventions from the health-sector perspective, as well as their } \\
\text { effects on mortality }\end{array}$ \\
\hline $\begin{array}{l}\text { Intervention } \\
\text { coverage }\end{array}$ & $\begin{array}{l}\text { Full coverage defined at } 85 \% \text {; rates of } \\
\text { scale-up defined using historical data } \\
\text { on so-called best performers among } \\
\text { similar groups of countries }\end{array}$ & $\begin{array}{l}\text { Full coverage defined as } 80 \% \text {; the HPP differs from EUHC } \\
\text { not in coverage level but in the scope of interventions } \\
\text { included }\end{array}$ & $\begin{array}{l}\text { Full coverage defined as } 95 \% \text { for most interventions in the } \\
\text { ambitious scenario, with a range from } 53 \% \text { to } 99 \% \text { depending on } \\
\text { intervention }\end{array}$ \\
\hline \multicolumn{4}{|c|}{ Estimated additional costs (including requisite investment in health system capacity) } \\
\hline $\begin{array}{l}\text { Low-income } \\
\text { countries }\end{array}$ & $\begin{array}{l}\text { US } \$(2011) 30 \text { billion annually between } \\
2016 \text { and } 2030\end{array}$ & $\begin{array}{l}\text { HPP: US } \$(2012) 32 \text { billion in 2030; EUHC: } \\
\text { US } \$(2012) 70 \text { billion in } 2030\end{array}$ & US\$(2012)64 billion in 2030 \\
\hline $\begin{array}{l}\text { Lower-middle- } \\
\text { income countries }\end{array}$ & $\begin{array}{l}\text { US } \$(2011) 61 \text { billion annually between } \\
2016 \text { and } 2030\end{array}$ & $\begin{array}{l}\text { HPP: US\$(2012)97 billion in 2030; EUHC: } \\
\text { US } \$(2012) 190 \text { billion in } 2030\end{array}$ & US $\$(2012) 185$ billion in 2030 \\
\hline \multicolumn{4}{|c|}{ 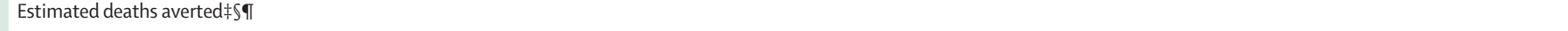 } \\
\hline $\begin{array}{l}\text { Low-income } \\
\text { countries }\end{array}$ & $\begin{array}{l}4.5 \text { million deaths averted per year } \\
\text { between } 2016 \text { and } 2030\end{array}$ & 2.0 million deaths averted in 2030 & 2.9 million deaths averted in 2030 \\
\hline $\begin{array}{l}\text { Lower middle- } \\
\text { income countries }\end{array}$ & $\begin{array}{l}5.8 \text { million deaths averted per year } \\
\text { between } 2016 \text { and } 2030\end{array}$ & 4.2 million deaths averted in 2030 & 6.1 million deaths averted in 2030 \\
\hline $\begin{array}{l}\text { Benefit cost analysis } \\
\text { undertaken }\end{array}$ & Yes & No & No \\
\hline \multicolumn{4}{|c|}{$\begin{array}{l}\text { EUHC=essential universal health coverage. HPP=highest priority package. SDGs=Sustainable Development Goals. *Separate estimates for the low-income and lower-middle-income country groups are provided. } \\
\text { †Reported results are for all included countries combined. } \neq D C P 3 \text { reports the number of premature deaths averted (ie, deaths younger than } 70 \text { years). SAverted deaths included stillbirths averted in the reports by } \\
\text { the Lancet Commission on Investing in Health }{ }^{21} \text { and WHO }{ }^{11} \text { but not in DCP3 }{ }^{53.57} \text { IIn the Lancet Commission report }{ }^{21} \text { and DCP3, the reported deaths averted included only deaths averted in children actually born } \\
\text { and women actually giving birth. Family planning averts unwanted pregnancies and hence potential deaths of women and children that would have occurred as a result of those averted pregnancies. } \\
\text { The difference is large. For low-income countries, results of a sensitivity analysis in Global Health } 2035^{21} \text { showed that the more comprehensive estimate was } 7 \cdot 5 \text { million deaths averted rather than the } 4.5 \text { million } \\
\text { deaths averted shown in this table. WHO's } 2017 \text { estimates }{ }^{11} \text { of deaths averted are based on the larger and more inclusive number. Ambitious scale-up of family planning services accounted for } 50 \% \text { of averted } \\
\text { child and maternal deaths and more than } 65 \% \text { of averted stillbirths in the WHO analysis (Stenberg K, Department of Health Systems Governance and Financing, WHO, personal communication). Sources: Jamison } \\
\text { et al (2013), }{ }^{21} \text { Boyle et al (2015), }{ }^{58} \text { Watkins et al (2017), }{ }^{57} \text { Watkins et al (2017), }{ }^{53} \text { and Stenberg et al (2017). }{ }^{11}\end{array}$} \\
\hline
\end{tabular}

Table 4: Costs and consequences of large-scale investment in health systems by the Lancet Commission on Investing in Health, Disease Control Priorities, 3rd edition (DCP3), and WHO

unlikely. The DCP3 model estimates what is technically and economically feasible given tools that are available at present. The results are indeed substantial—and are viable options for decision makers. But substantial resources are required, and the goals are incompletely met. The actual decision to commit resources remains, of course, in the hands of national authorities.

\section{Costs}

The DCP3 costing model provides two estimates of costs for the health-system component of each of DCP3's 21 essential packages. ${ }^{57}$ The first was an estimate of how much additional funding it would take (in the 2015 cost and demographic environment) to implement each package to the extent judged feasible. The packages were designed so that for most cases full implementation (ie, $80 \%$ effective coverage) was judged feasible by 2030 . The second estimate was of total cost for the package defined as incremental cost plus an estimate of the amount already (in 2015) being spent on the intervention. The model estimates these costs both for low-income countries and for lower-middle-income countries. Some interventions were included in several packages, which was a natural outcome of a package formulation process that delineated packages as areas of concern to specific professional communities, such as surgeons or reproductive health specialists. Eliminating this duplication resulted in 218 distinct EUHC interventions. This implies that the sum of the package costs will exceed the cost of providing all packages. The subset of UHC that was judged (by explicit criteria) to be highest priority (ie, HPP) was costed in the same way 
as for EUHC. Costs should be interpreted as long-term steady state costs-costs that include training of staff to replace retirements and investment to counter depreciation of equipment and facilities. Naturally, country-specific applications will be built on countryspecific intervention lists and cost structures. The DCP3 costing model provides a tool to assist national health technology assessment units in developing national specifications, including analyses of a particular platform or package. Decision makers often wish to assess whether a particular intervention should be in or out, and Susan Horton ${ }^{33}$ has summarised DCP3's intervention-specific cost-effectiveness analyses.

The expenditure increases required above as a percentage of gross national income (GNI) are shown in table 2). Additional detail is available in the appendix, and costs by package are available in chapter 3 of DCP3 volume $9 .{ }^{42}$ Just a small fraction of reasonably anticipated economic growth in most countries would cover the incremental costs of EUHC, although achieving the increased percentage of GNI required would require substantial reordering of public sector priorities. ${ }^{21}$ Additional (incremental) costs needed are substantial relative to current levels of public expenditure on health. In principle, projections could be made of changes in both the tradeable and non-tradeable components of cost, of the responsiveness of costs to demography (and in particular to fertility decline), and on whether improved transport and other infrastructure might reduce our estimates of the cost of expanding coverage to parts of the population that are ever more difficult to reach. This will be worthwhile in a country-specific context, but for purposes of reasonable overall cost estimates, we judged that adding these layers of assumption would add little or nothing to the information content of table 2 .

Table 3 presents the DCP 3 costing model's assessment of cost by platform and cost by degree of intervention urgency. More than half of our calculated costs occur at the health-centre level. For EUHC, another 15-25\% each of incremental expenditures would go to the first-level hospital and to the community level. The health-systems implications for increasing intervention coverage plausibly differ markedly by urgency. Although DCP3 has taken a step forward with its systematic classification and costing, much work remains before implications for health systems are well understood. Continuing interventions require appropriate community capacity for delivery. Examples include antiretroviral therapy or antihypertensive therapy. Half of estimated incremental costs are needed to finance continuing intervention. Urgent interventions (eg, for trauma or obstructed labour) require that first-level hospitals be accessible quickly. ${ }^{27}$ About a quarter to a third of incremental costs are required to provide this capacity. Time-bound but non-urgent interventions (eg, cataract extraction) allow patients to be accumulated over space and time with concomitant potential for efficiency and quality resulting from high volume. The numbers of interventions on each platform according to degree of urgency are available in the appendix.

Reduction in mortality and the costs of major healthsystem investments were also modelled by the Lancet Commission on Investing in Health ${ }^{21}$ and WHO. ${ }^{11}$ The estimates and differences between these analyses and those of DCP3 are summarised in table 4.

\section{Conclusion}

The nine volumes of DCP3 provide a granular assessment of technical and policy alternatives facing decision makers and opinion leaders in LMICs. DCP3 is particularly relevant as achievement of EUHC relies increasingly on greater domestic finance, with global developmental assistance in health focusing more on global public goods. In this Review, we have summarised the content of a model concept of EUHC and point to specific priorities for intersectoral action for health (panel 1).

\section{Contributors}

DTJ generated the basic plan for this study with inputs from AA, CNM, $\mathrm{RN}$, and DGW. DTJ prepared the first draft with input and revisions from all authors. All authors approved the final draft before submission. DTJ had responsibility for submitting for publication.

\section{Declaration of interests}

DTJ, AA, CNM, RN, DGW, KD, and CL report grants from the Bill \& Melinda Gates Foundation during the conduct of the study. KAF reports personal fees from the Centre for Global Health, Nationa Cancer Institute during the conduct of the study. TG reports personal fees from Teva Pharmaceuticals and grants from United HealthCare Services and Novartis, outside the submitted work. FMK reports grants from Pfizer, Mayday Fund, American Cancer Society, Roche, CRDF Global, JM Foundation, Grunenthal, and GDS, during the conduct of the study; and grants, personal fees, and non-financial support from Roche, Pfizer, Novartis, GlaxoSmithKline, Merck/EMD Serono,

Asociacion Mexicana de Industrias de Investigacion Farmaceutica, Sanofi, Chinoin, and NADRO, outside the submitted work. MEK reports personal fees from Merck for Mothers, outside the submitted work. DP reports grants from the University of Washington, during the conduct of the study. DAPB and DGW are employees of the

Bill \& Melinda Gates Foundation, and SB, CM, and JS have previously worked for the Bill \& Melinda Gates Foundation, which funds the DCP3 series. DGW has managed the Disease Control Priorities Network grant since 2011. GH was previously affiliated with the Water and Sanitation Program, World Bank, Washington, DC, USA. DC, AC, TD, JM, and TR are staff members of the World Health Organization. The authors alone are responsible for the views expressed in this Review and they do not necessarily represent the decisions, policy, or views of the World Health Organization. All other authors declare no competing interests.

\section{Acknowledgments}

The Bill \& Melinda Gates Foundation funded DCP3 as an element of its Disease Control Priorities Network grant to the University of Washington. The views expressed herein are those of the authors and do not necessarily reflect the official policy or position of the Bill \& Melinda Gates Foundation. Many institutions have made available the time of their staff and they are specifically acknowledged in each volume. The views expressed in this paper are those of individual authors and not of the institutions with which they are affiliated. We acknowledge three institutions that have played key roles in DCP3. One is the World Bank, original home for the DCP series and accomplished publisher of its products. Within the World Bank, Carlos Rossel and Mary Fisk oversaw the editing and publication of the series, and served as important champions for DCP3. The second is the Inter-Academy Medical Panel (IAMP) and its US affiliate, the National 
Academy of Medicine (NAM). IAMP/NAM have organised a peer-review process to cover chapters in the nine volumes, and they established an Advisory Committee to the Editors, chaired by Anne Mills, of enormous value. The Department of Global Health, University of Washington, has provided a congenial home for DCP for the past 5 years. We acknowledge the intellectual and practical support of the department's two chairs during this period, King Holmes and Judith Wasserheit. We thank Shamelle Richards, Tiffany Wilk, and Nazila Dabestani for their administrative and research support to the production of DCP3. Brianne Adderley has ably served DCP3 as Project Manager since the beginning, and we owe her a very particular thanks. We thank the referees for valuable and constructive comments.

References

1 Jamison DT, Mosley WH, Measham AR, Bobadilla JL, eds. Disease control priorities in developing countries, 1st edn. New York: Oxford University Press, 1993.

2 Harlan WR, Harlan LC, Oii WL. Changing disease patterns in developing countries: the case of Malaysia. In: Leaverton P, Massi L, eds. Health information systems. New York: Praeger Scientific, 1984

3 Jamison DT, Evans JR, King T, Porter I, Prescott N. China: the health sector. Washington, DC: World Bank, 1984

4 Evans JR, Lashman Hall K, Warford J. Shattuck lecture. Health care in the developing world: problems of scarcity and choice. N Engl J Med 1981; 305: 1117-27.

5 Bobadilla JL, Frenk J, Lozano R, Frejka T, Claudio S. Chapter 3. The epidemiologic transition and health priorities. In Jamison DT, Mosley WH, Measham AR, Bobadilla JL, eds. Disease control priorities in developing countries, 1st edn. New York: Oxford University Press, 1993

6 Frenk J, Bobadilla JL, Sepulveda J, Lopez-Cervantes M. Health transition in middle-income countries: new challenges for health care. Health Policy Plan 1989; 4: 29-39.

$7 \quad$ World Bank. World development report 1993. Investing in health. New York: Oxford University Press, 1993.

8 Summers LH. Introduction. In: Jamison DT, Gelband $\mathrm{H}$, Horton S, et al, eds. Disease control priorities, 3rd edn. Washington, DC: World Bank (in press).

9 Gates B, Gates M. Foreword. In: Jamison DT, Gelband H, Horton S, et al, eds. Disease control priorities, 3rd edn. Washington, DC: World Bank (in press).

10 Jamison DT, Breman JG, Measham AR, et al. Disease Control Priorities in developing countries, 2nd edn. New York, Washington, DC: Oxford University Press, World Bank, 2006.

11 Stenberg K, Hanssen O, Edejer TT-T, et al. Financing transformative health systems towards achievement of the health Sustainable Development Goals: a model for projected resource needs in 67 low-income and middle-income countries. Lancet Glob Health 2017; 5: e875-87.

12 Skolnik R. Global Health 101, 3rd edition. Burlington, MA: Jones \& Bartlett Learning, 2016.

13 Jamison DT, Jha P, Laxminarayan R, Ord T. Chapter 7. Infectious disease, injury, and reproductive health. In: Lomborg B, ed. Global problems, smart solutions: costs and benefits. New York: Cambridge University Press, 2013.

14 Bloom BR, Michaud CM, La Montagne JR, Simonsen L. Chapter 4. Priorities for global research and development of interventions. In: Jamison DT, Breman JG, Measham AR, et al, eds. Disease control priorities in developing countries, 2nd edn. Washington, DC: World Bank, Oxford University Press, 2006.

15 Weatherall D, Greenwood B, Chee HL, Wasi P. Chapter 5. Science and technology for disease control: past, present, and future. In: Jamison DT, Breman JG, Measham AR, et al, eds. Disease control priorities in developing countries, 2nd edn. Washington, DC: World Bank, Oxford University Press, 2006.

16 Mahmoud A, Danzon PM, Barton JH, Mugerwa RD. Chapter 6. Product development priorities. In: Jamison DT, Breman JG, Measham AR, et al, eds. Disease control priorities in developing countries, 2nd edn. Washington, DC: World Bank, Oxford University Press, 2006.

17 Meltzer D. Chapter 7. Economic approaches to valuing global health research. In: Jamison DT, Breman JG, Measham AR, et al, eds. Disease control priorities in developing countries, 2 nd edn. Washington, DC: World Bank, Oxford University Press, 2006.
18 Bundy DAP, de Silva N, Horton S, Jamison DT, Patton GC. Disease control priorities, 3rd edn. Volume 8 . Child and adolescent health and development. Washington, DC: World Bank, 2017.

19 Trimble EL, Rajaraman P, Chao A, et al. Chapter 15. The need for national commitments to cancer research to guide public health investment and practice. In: Gelband H, Jha P, Sankaranarayanan R, Horton S, eds. Disease control priorities, 3rd edn. Volume 3. Cancer. Washington, DC: World Bank, 2015.

20 Pradhan E, Suzuki EM, Martínez S, Schäferhoff M, Jamison D. Chapter 30 . The effects of education quantity and quality on child and adult mortality: their magnitude and their value. In: Bundy DAP, de Silva N, Horton SE, Jamison DT, Patton GC, eds. Disease control priorities, 3rd edn. Volume 8 . Child and adolescent health and development. Washington, DC: World Bank, 2017.

21 Jamison DT, Summers LH, Alleyne G, et al. Global health 2035: a world converging within a generation. Lancet 2013; 382: 1898-955.

22 Kydland FE, Mundell R, Schelling T, Smith V, Stokey N. Expert panel ranking. In: Lomborg B, ed. Global problems, smart solutions: costs and benefits. Cambridge: Cambridge University Press, 2013: 701-16.

23 Ghebreyesus TA. All roads lead to universal health coverage. Lancet Glob Health 2017; 5: e839-40.

24 Glassman A, Giedion U, Smith PC. What's in, what's out: designing benefits for universal health coverage. Washington, DC: Center for Global Development, 2017.

25 Bendavid E, Ottersen T, Liu P, et al. Chapter 16. Development assistance for health. In: Jamison DT, Gelband H, Horton S, et al, eds. Disease Control Priorities, 3rd edn. Volume 9. Disease control priorities: improving health and reducing poverty. Washington, DC: World Bank (in press).

26 Schäferhoff M, Fewer S, Kraus J, et al. How much donor financing for health is channelled to global versus country-specific aid functions? Lancet 2015; 386: 2436-41.

27 Reynolds T, Sawe H, Rubiano AM, Shin SD, Wallis L, Mock CN Chapter 13. Strengthening health systems to provide emergency care In: Jamison DT, Gelband H, Horton S, et al, eds. Disease control priorities, 3rd edn. Volume 9 . Disease control priorities: improving health and reducing poverty. Washington, DC: World Bank (in press).

28 Peabody J, Shimkhada R, Adeyi O, Wang H, Broughton E, Kruk M. Chapter 10. Quality of care. In: Jamison DT, Gelband H, Horton S, et al, eds. Disease control priorities, 3rd edn. Volume 9. Disease control priorities: improving health and reducing poverty. Washington, DC: World Bank (in press).

29 Rumbold B, Baker R, Ferraz O, et al. Universal health coverage, priority setting, and the human right to health. Lancet 2017; 390: 712-14.

30 Jamison, DT. Disease control priorities: improving health and reducing poverty. Lancet 2015; published online Feb 4. http://dx.doi.org/10.1016/S0140-6736(15)60097-6.

31 Bates MA, Glennerster R. The generalizability puzzle. Stanford Social Innovation Review, 2017; summer. https://ssir.org/ articles/entry/the_generalizability_puzzle (accessed Sept 26, 2017).

32 Ozler B. Learn to live without external validity. Impact evaluations World Bank blog. Nov 4, 2013. https://blogs.worldbank.org/ impactevaluations/learn-live-without-external-validity (accessed Sept 26, 2017)

33 Horton S. Chapter 7. Cost-effectiveness analysis. In: Jamison DT, Gelband H, Horton S, et al, eds. Disease control priorities, 3rd edn. Volume 9. Disease control priorities: improving health and reducing poverty. Washington, DC: World Bank (in press).

34 Chang AY, Horton S, Jamison DT. Chapter 9. Benefit-cost analysis. In: Jamison DT, Gelband H, Horton S, et al, eds. Disease control priorities, 3rd edn. Volume 9. Disease control priorities: improving health and reducing poverty. Washington, DC: World Bank (in press).

35 Verguet S, Jamison DT. Chapter 8. Health policy analysis: applications of extended cost-effectiveness analysis methodology. In: Jamison DT, Gelband H, Horton S, et al, eds. Disease control priorities, 3rd edn. Volume 9. Disease control priorities: improving health and reducing poverty. Washington, DC: World Bank (in press).

36 Essue B, Laba T, Knaul FM, et al. Chapter 6. Economic burden of chronic ill health and injuries for households in low- and middleincome countries. In: Jamison DT, Gelband H, Horton S, et al, eds. Disease control priorities, 3rd edn. Volume 9. Disease control priorities: improving health and reducing poverty. Washington, DC: World Bank (in press). 
37 Verguet S, Laxminarayan R, Jamison DT. Universal public finance of tuberculosis treatment in India: an extended cost-effectiveness analysis. Health Economics 2015; 24: 318-32.

38 Mills JA, Marks E, Reynolds T, Cieza A. Chapter 15. Rehabilitation: essential along the continuum of care. In: Jamison DT, Gelband H, Horton S, et al, eds. Disease control priorities, 3rd edn. Volume 9. Disease control priorities: improving health and reducing poverty. Washington, DC: World Bank (in press).

39 Fleming K, Naidoo M, Wilson M, et al. Chapter 11. High quality diagnosis: an essential pathology package. In: Jamison DT,

Gelband H, Horton S, et al, eds. Disease control priorities, 3rd edn. Volume 9. Disease control priorities: improving health and reducing poverty. Washington, DC: World Bank (in press).

40 Krakauer E, Ali Z, Arreola H, Bhadelia A, Connor S, de Lima L. Chapter 12. Palliative care. In: Jamison DT, Gelband H, Horton S, et al, eds. Disease control priorities, 3rd edn. Volume 9. Disease control priorities: improving health and reducing poverty. Washington, DC: World Bank (in press).

41 Madhav N, Oppenheim B, Gallivan M, Mulembakani P, Rubin E, Wolfe N. Chapter 17. Pandemics: risks, impacts, and mitigation. In: Jamison DT, Gelband H, Horton S, et al, eds. Disease control priorities, 3rd edn. Volume 9. Disease control priorities: improving health and reducing poverty. Washington, DC: World Bank (in press)

42 Jamison DT, Alwan A, Mock CN, et al. Chapter 1. Universal health coverage and intersectoral action for health. In: Jamison DT, Gelband H, Horton S, et al, eds. Disease control priorities, 3rd edn. Volume 9. Disease control priorities: improving health and reducing poverty. Washington, DC: World Bank (in press).

43 Watkins DA, Jamison DT, Mills AJ, et al. Chapter 3. Universal health coverage and essential packages of care. In: Jamison DT, Gelband $\mathrm{H}$ Horton S, et al, eds. Disease control priorities, 3rd edn. Volume 9. Disease control priorities: improving health and reducing poverty. Washington, DC: World Bank (in press).

44 Watkins DA, Nugent RA, Saxenian H, et al. Chapter 2. Intersectoral policy priorties for health. In: Jamison DT, Gelband $\mathrm{H}$, Horton S, et al, eds. Disease control priorities, 3rd edn. Volume 9. Disease control priorities: improving health and reducing poverty. Washington, DC: World Bank (in press).

45 Landrigan PJ, Fuller R, Acosta NJR, et al. The Lancet Commission on pollution and health. Lancet 2017; published online Oct 19. http://dx.doi.org/10.1016/ S0140-6736(17)32345-0.

46 GBD 2016 Risk Factors Collaborators. Global, regional, and national comparative risk assessment of 84 behavioural, environmental and occupational, and metabolic risks or clusters of risks, 1990-2016: a systematic analysis for the Global Burden of Disease Study 2016. Lancet 2017; 390: 1345-422.

47 Afshin A, Micha R, Webb M, et al. Chapter 6. Effectiveness of dietary policies to reduce noncommunicable diseases. In: Prabhakaran D, Anand S, Gaziano T, Mbanya JC, Wu Y, Nugent RA, eds. Disease control priorities, 3rd edn. Volume 5. Cardiovascular, respiratory, and related disorders. Washington, DC: World Bank, 2017
48 Dehghan M, Mente A, Zhang X, et al. Associations of fats and carbohydrate intake with cardiovascular disease and mortality in 18 countries from five continents (PURE): a prospective cohort study. Lancet 2017; published online Aug 29. http://dx.doi.org/10.1016/ S0140-6736(17)32252-3.

49 Bazzano LA, Hu T, Reynolds K, et al. Effects of low-carbohydrate and low-fat diets: a randomized trial. Ann Intern Med 2014; 161: $309-18$.

50 Weiser TG, Gawande AA. Chapter 16. Excess surgical mortality: strategies for improving quality of care. In: Debas HT, Donkor P, Gawande AA, Jamison DT, Kruk ME, Mock CN, eds. Disease contro priorities, 3rd edn. Volume 1. Essential surgery. Washington, DC: World Bank, 2015: 279-306.

51 Mills A, Rasheed F, Tollman S. Chapter 3. Strengthening health systems. In: Jamison DT, Breman JG, Measham AR, et al, eds. Disease control priorities in developing countries, 2nd edn. Washington, DC: World Bank, 2006.

52 Norheim OF, Jha P, Admasu K, et al. Avoiding $40 \%$ of the premature deaths in each country, 2010-30: review of national mortality trends to help quantify the UN Sustainable Development Goal for health. Lancet 2015; 385: 239-52.

53 Watkins DA, Norheim OF, Jha P, Jamison DT. Reducing mortality within universal health coverage: the DCP3 model. DCP3 Working Paper No. 21. Washington, DC: World Bank, 2017.

54 Mathers C, Stevens G, Hogan D, Mahanani A, Ho J. Chapter 4. Global and Regional Causes of Death: Patterns and Trends, 2000-15. In: Jamison DT, Gelband H, Horton S, Jha P, Laxminarayan R, Mock C, Nugent R, eds. Disease control priorities, 3rd edn. Volume 9. Disease control priorities: improving health and reducing poverty. Washington, DC: World Bank (in press).

55 World Bank. World development indicators, 2014. Washington, DC: World Bank, 2014.

56 United Nations Department of Economic and Social Affairs. World population prospects: 2017 revision, key findings and advance tables. Report ESA/P/WP/248. New York, NY: UN DESA Population Division, 2017

57 Watkins DA, Qi J, Horton SE, Jamison DT. Costing universal health coverage: the DCP3 model. DCP3 Working Paper No. 20. Washington, DC: World Bank, 2017.

58 Boyle CF, Levin C, Hatefi A, Madriz S, Santos N. Achieving a "grand convergence" in global health: modeling the technical inputs, costs, and impacts from 2016 to 2030. PLoS One 2015; 10: $\mathrm{e} 0140092$ 